\title{
No country or continent is on its own in the ongoing COVID-19 pandemic
}

Kari Johansen ${ }^{1}$, Hanna Nohynek ${ }^{2}$

1. Independent public health expert, Stockholm, Sweden

2. Finnish Institute for Health and Welfare (THL), Helsinki, Finland

Correspondence: Hanna Nohynek (hanna.nohynek@thl.fi)

Johansen Kari, Nohynek Hanna. No country or continent is on its own in the ongoing COVID-19 pandemic. Euro Surveill. 2021;26(17):pii=2100430. https://doi. org/10.2807/1560-7917.ES.2021.26.17.2100430

Article submitted on 29 Apr 2021 / accepted on 29 Apr 2021 / published on 29 Apr 2021

Now 15 months into the coronavirus disease (COVID19) pandemic, morbidity and mortality have been considerable and have affected people worldwide, irrespective of country of origin, socioeconomic status or genetic background. Strict lockdowns have lowered disease incidence and eased the burden on healthcare systems. Still, first data from early adapters of largescale vaccination campaigns suggest that COVID-19 vaccines are the most effective measure against the disease and should allow for a gradual re-opening of society. However, a number of issues must be resolved before life similar to before the pandemic can resume. This year's European Immunization Week, from 26 April to 2 May, is an opportunity to celebrate the achievements of the COVID-19 pandemic response, as well as discuss the remaining challenges in Europe and globally, such as limited vaccine availability, lack of equitable vaccine distribution and the implications of the emerging severe acute respiratory syndrome coronavirus 2 (SARS-CoV-2) variants of concern (VOCs).

Following the identification of SARS-CoV-2 in early January 2020 [1], vaccine candidates began to be developed at an unprecedented pace. A year later, over 10 candidates have received emergency use approvals or conditional marketing authorisations by either national regulatory agencies, the European Medicines Agency (EMA) or the World Health Organization (WHO) prequalification system. On 27 April 2021, WHO listed 276 vaccine candidates in its global COVID-19 candidate vaccine landscape and tracker, of which 92 are being tested in clinical phase 1,2 or 3 trials [2]. Among the 10 different vaccine production technology platforms listed, the most common are protein subunit, non-replicating viral vectors, inactivated whole virion and mRNA vaccines, with the protein subunit vaccines in need of adjuvants. The recommended priming schedules vary between administration of 1 to 3 doses, delivered 2 to 12 weeks apart, with the most common schedule being 2 doses administered 3 to 4 weeks apart. The route of administration varies from intramuscular to intradermal, subcutaneous, oral or intranasal.

The urgency of the pandemic led to a paradigm shift in vaccine clinical trials. The different trial phases were run in parallel rather than in sequence, and national regulatory authorities and the EMA agreed to intensive advising and rolling review, to speed up the licensure process. An a priori threshold for approval of $50 \%$ efficacy, with a lower bound of $95 \%$ confidence interval of $30 \%$, was accepted [3]. For safety, a minimum period of 2 months of follow-up was agreed, which is justified, as most known adverse events are recognised within 6 weeks from vaccination. By April 2021, four COVID-19 vaccines received conditional marketing authorisation in the European Union (EU) [4] and a rolling regulatory review has been initiated for four additional vaccine candidates, adding further production technologies to the portfolio.

Several of the globally authorised vaccines, especially the mRNA and adenovirus-vectored ones, have exceeded expectations and protect remarkably well against death and severe disease. After only one dose, significant protection against hospitalisation was observed 4 weeks post immunisation, for both vaccine types $[5,6]$. In addition, these vaccines protect against infection and reduce viral load, thereby likely also reducing transmission and contributing to indirect protection in the community [7].

Vaccine candidates have been developed and associated clinical trials have been conducted with considerable public and private donations through national governments, institutional funders and others, in collaboration with smaller- and larger-scale academic, governmental and private vaccine developers. The rapid development benefited from many years of basic research establishing vaccine production technology platforms for similar pathogens, in particular severe 
TABLE 1

Evidence and factors to be considered in national vaccination decision-making

Evidence to recommendation domain

Question

\begin{tabular}{|l|r|}
\hline Public health problem & Is the problem of public health importance? \\
\hline Benefits and harms & $\begin{array}{c}\text { How substantial are the desirable anticipated effects? } \\
\text { How substantial are the undesirable anticipated effects? }\end{array}$ \\
\hline Values & Do the desirable effects outweigh the undesirable effects? \\
\hline Acceptability & $\begin{array}{r}\text { Does the target population feel the desirable effects are large relative to the } \\
\text { undesirable effects? }\end{array}$ \\
\hline Feasibility & Is there important variability in how patients value the outcomes? \\
\hline Resource use & Is the intervention acceptable to key stakeholders? \\
\hline Equity & Is the intervention feasible to implement? \\
\hline
\end{tabular}

Adapted from the Standard Operating Procedure of the German Standing Committee on Vaccinations (STIKO) for the systematic development of vaccination recommendations [31].

acute respiratory syndrome coronavirus 1 (SARS-CoV-1) and Middle East respiratory syndrome coronaviruses (MERS-CoV). Through the joint EU procurement mechanism, all four conditionally authorised vaccines have been delivered to all EU countries, not necessarily prorata but in different proportions and in line with country requests, which have differed, as evidenced in the European Centre for Disease Prevention and Control's (ECDC) vaccine tracker on the COVID-19 vaccines distributed in the EU/European Economic Area (EEA) countries [8].

In many countries, recommendations on vaccine use in the national programmes are based on grading the available scientific evidence in a systematic and transparent manner (Table 1). Depending on the funding basis of the programme, cost-effectiveness analyses may also be applied to support decision-making. However, for prevention of COVID-19, cost has-for most EU countries-been a secondary issue at the national level due to the EU joint procurement mechanism, though this is different at the global level, both in the bilateral agreements and through the COVID19 Vaccines Global Access (COVAX) mechanism [9]. Globally, the WHO Strategic Advisory Group of Experts (SAGE) has tried to guide countries that are introducing COVID-19 vaccines while facing a supply shortage. The 'WHO SAGE values framework for the allocation and prioritisation of COVID-19 vaccination' emphasises the six common values that countries should respect while planning the deployment of COVID-19 vaccines: human well-being, equal respect, global and national equity, reciprocity and legitimacy [10]. Further, the 'WHO SAGE Roadmap For Prioritizing Uses Of COVID-19 Vaccines In The Context Of Limited Supply - An approach to inform planning and subsequent recommendations based upon epidemiologic setting and vaccine supply scenarios' draws three basic scenarios on how to use the value framework mentioned above in different epidemiological settings, with low-, middle-, and highcirculation of SARS-CoV-2 [11]. In all of these scenarios, frontline healthcare workers and older adults are the most vulnerable population groups and should be vaccinated first.

National Immunization Technical Advisory Groups (NITAGs) or equivalent committees have provided advice to their governments using these WHO SAGE frameworks and their own decision-making processes on how to best use these new vaccines. In Europe, the EU/EEA NITAG Collaboration network [12], coordinated by ECDC, has provided a platform for useful exchange among those in charge of expert advice for national vaccination programmes. However, as COVID-19 epidemiology and disease burden have varied across countries since the beginning of the pandemic, there have been differences between countries in interpreting benefit-risk ratios and deciding on vaccination prioritisation order. This was observed in national decisions relating to the early use of Vaxzevria (formerly COVID19 Vaccine AstraZeneca, AstraZeneca, Cambridge, University of Oxford, Oxford, United Kingdom (UK)), in the absence of robust trial data among older adults (> 65 years old), and again when some countries made changes to their vaccination programmes after the vaccine safety signal noting reports of rare thrombotic thrombocytopenic syndrome among those administered the same vaccine emerged [13-16]. Both of these examples have contributed to the current differences between country-specific recommendations for this vaccine in the EU.

The European Commission has set the target of $70 \%$ coverage of a first dose of COVID-19 vaccines in all countries by July 2021. As at the end of April 2021, the cumulative uptake of $26.5 \%$ for at least one vaccine dose in the EU [8] is lower than in a few other high-income countries like Israel, the UK and the United States (US) [17]. However, from a global perspective-with an average of $7.4 \%$ for the first dose, as at 26 April 2021 [17]-most EU countries are doing well. Vaccination programmes have also started in all 
Future challenges identified and necessary monitoring and evaluation activities to guide the evidence-based short- and long-term vaccine and vaccination response to the COVID-19 pandemic in the European Union/European Economic Area and globally

\begin{tabular}{|c|c|c|}
\hline Domain & Identified challenges & Necessary monitoring and evaluation activities \\
\hline \multirow{4}{*}{ Epidemiology } & $\begin{array}{c}\text { Routinely monitoring infected cases, } \\
\text { hospitalised cases, cases in intensive care and } \\
\text { mortality }\end{array}$ & Ensure timely reporting \\
\hline & \begin{tabular}{|c|} 
Reports on age and risk groups for respective \\
category above
\end{tabular} & Ensure timely reporting \\
\hline & $\begin{array}{l}\text { Reports on co-infections (e.g. SARS-CoV-2 + } \\
\text { influenza, RSV or measles upon return) }\end{array}$ & Ensure timely reporting \\
\hline & $\begin{array}{c}\text { Identify changes in epidemiology such as } \\
\text { new clusters or increased severity in a timely } \\
\text { manner }\end{array}$ & $\begin{array}{c}\text { Ensure timely investigations and reporting on epidemiological changes } \\
\text { at the EU/EEA level and globally that may impact vaccine composition } \\
\text { or vaccination recommendations }\end{array}$ \\
\hline \multirow{5}{*}{$\begin{array}{l}\text { Circulating SARS- } \\
\text { CoV-2 viruses }\end{array}$} & Availability of diagnostics & $\begin{array}{l}\text { Ensure diagnostics offered generously and results reported in a timely } \\
\text { manner }\end{array}$ \\
\hline & & Ensure diagnostics of possible co-infections \\
\hline & $\begin{array}{l}\text { Identification and monitoring incidence of } \\
\text { SARS-CoV-2 variants of interest and concern }\end{array}$ & $\begin{array}{l}\text { Whole genome sequencing of representative samples and timely } \\
\text { reporting }\end{array}$ \\
\hline & $\begin{array}{l}\text { Assessment of transmissibility, severity and } \\
\text { vaccine escape }\end{array}$ & $\begin{array}{c}\text { Ensure a functioning EU/EEA-level and support to a global framework } \\
\text { for rapid assessments of circulating variants of interest and concern in } \\
\text { a timely manner }\end{array}$ \\
\hline & Assessment of need for updated vaccines & $\begin{array}{l}\text { Support to a global framework for rapid assessment of new variants of } \\
\text { concern and timely recommendations for updates of COVID-19 vaccines }\end{array}$ \\
\hline \multirow{4}{*}{$\begin{array}{l}\text { Vaccine } \\
\text { availability }\end{array}$} & Timely vaccine development & $\begin{array}{l}\text { Support to continued vaccine development, clinical trials and if needed } \\
\text { updated vaccines in response to new emerging SARS-CoV-2 variants of } \\
\text { concern }\end{array}$ \\
\hline & $\begin{array}{l}\text { Vaccine production capacity to fulfil public } \\
\text { health recommendations }\end{array}$ & $\begin{array}{c}\text { Map and ensure production and filling capacity in a sufficient number } \\
\text { of EU/EEA sites to serve the EU/EEA population } \\
\text { Ensure access to raw materials for vaccine production }\end{array}$ \\
\hline & National and EU equity & Map and ensure vaccine equity within and between EU/EEA countries \\
\hline & Global equity & Map and ensure vaccine equity within and between countries globally \\
\hline
\end{tabular}

COVID-19: coronavirus disease; EU/EEA: European Union/European Economic Area; RSV: respiratory syncytial virus; SARS-CoV-2: severe acute respiratory syndrome coronavirus 2 .

non-EU countries in the WHO European Region, while introduction of COVID-19 vaccines is still pending in 14 other countries worldwide [17]. Whether vaccine coverage can reach a high enough threshold to provide community immunity in the EU, remains to be seen.

Newly emerging SARS-CoV-2 variants that could be capable of escaping vaccine protection may present a challenge to COVID-19 control and the future scenario may be similar to what we observe with vaccines against influenza, where we seldom expect community immunity. Based on its experience of routinely updating seasonal influenza vaccine strains, WHO is currently developing a framework for assessing new SARS-CoV-2 variants that will contain a process for variant selection to be included in future multivalent COVID-19 vaccines, if found to be safe and effective in the ongoing clinical trials [18-20]. This global framework is not ready yet, but regulatory agencies such as the EMA and the US Food and Drug Administration have developed guidelines for vaccine developers on how to test updated COVID-19 vaccines [21,22]. Further, many EU countries have made breakthrough infections following vaccination notifiable, and it is important that SARSCoV-2 viruses that are able to cause infection despite prior vaccination undergo whole genome sequencing. Safety and effectiveness studies of COVID-19 vaccine in use are also being set up using different study designs under the new EMA-ECDC collaboration framework that will address variant-specific performance [23].

Even once $70 \%$ COVID-19 vaccine coverage among adults is reached, there are additional aspects that need careful consideration: waning immunity, the role of children and adolescents in disease transmission, availability of vaccines for children and guidance on how to best use vaccines in pregnant women, as well as immunocompromised individuals. Whether booster doses will be needed for all or some of the vaccine candidates is currently uncertain. Clinical trials have been initiated with candidates containing one or several of the newly emerged variants to possibly be used in yearly boosters or more often, if needed. Several manufacturers are far advanced in developing childhood COVID-19 vaccines, and the first extended vaccine indication for one or several vaccines may come 
Future challenges identified and necessary monitoring and evaluation activities to guide the evidence-based short- and long-term vaccine and vaccination response to the COVID-19 pandemic in the European Union/European Economic Area and globally

\begin{tabular}{|c|c|c|}
\hline Domain & Identified challenges & Necessary monitoring and evaluation activities \\
\hline \multirow{17}{*}{$\begin{array}{l}\text { Vaccine } \\
\text { performance }\end{array}$} & \multirow[t]{2}{*}{ Vaccine coverage } & $\begin{array}{c}\text { Ensure routine product-specific documentation of COVID-19 vaccines } \\
\text { administered to individual citizens in immunisation registries available } \\
\text { over time to support decisions on administration of booster doses, if } \\
\text { needed }\end{array}$ \\
\hline & & $\begin{array}{c}\text { Timely reporting of vaccination coverage by age and risk groups at } \\
\text { national and EU levels }\end{array}$ \\
\hline & \multirow{7}{*}{ Vaccine safety } & $\begin{array}{c}\text { Ensure routine safety monitoring and timely reporting and publishing in } \\
\text { a transparent manner at EU/EEA level }\end{array}$ \\
\hline & & $\begin{array}{l}\text { Ensure vaccine safety signal detection system and validation at the EU/ } \\
\text { EEA level }\end{array}$ \\
\hline & & Develop case definition if unknown adverse event \\
\hline & & $\begin{array}{c}\text { Ensure background incidence rates available for all adverse events } \\
\text { of special interest in a representative number of EU/EEA countries for } \\
\text { observed versus expected analysis and development of regulatory } \\
\text { assessments of benefit-risk ratio }\end{array}$ \\
\hline & & $\begin{array}{l}\text { Ensure conduct of product-specific pharmacoepidemiologic studies } \\
\text { to be reported to public health and regulators in a timely manner and } \\
\text { published in a transparent manner }\end{array}$ \\
\hline & & $\begin{array}{l}\begin{array}{l}\text { Explore if product-specific, real-time scientific studies can be } \\
\text { performed }\end{array}\end{array}$ \\
\hline & & $\begin{array}{l}\text { Ensure vaccine safety communication channels are in place should a } \\
\text { vaccine safety signal occur }\end{array}$ \\
\hline & \multirow{5}{*}{ Vaccine effectiveness } & $\begin{array}{c}\text { Ensure conduct of product-specific vaccine effectiveness studies } \\
\text { addressing outcomes such as any COVID-19 infection, hospitalisation } \\
\text { due to COVID-19, death due to COVID-19, long COVID-19, transmission } \\
\text { and viral shedding by SARS-CoV-2 variants to be reported to } \\
\text { public health and regulators in a timely manner and published in a } \\
\text { transparent manner }\end{array}$ \\
\hline & & $\begin{array}{l}\text { Ensure conduct of product-specific vaccine effectiveness studies } \\
\text { in special groups (comorbidities, children, pregnant women, } \\
\text { immunocompromised, etc.) }\end{array}$ \\
\hline & & $\begin{array}{l}\text { Ensure conduct of product-specific vaccine effectiveness studies } \\
\text { addressing different time intervals between dose } 1 \text { and } 2\end{array}$ \\
\hline & & $\begin{array}{l}\text { Ensure conduct of product-specific vaccine effectiveness studies } \\
\text { addressing mix and match of authorised COVID-19 vaccines }\end{array}$ \\
\hline & & $\begin{array}{l}\begin{array}{l}\text { Explore if product-specific real-time effectiveness studies can be } \\
\text { performed }\end{array} \\
\end{array}$ \\
\hline & \multirow{2}{*}{ Vaccine escape } & $\begin{array}{l}\text { Ensure seroepidemiological studies to monitor for waning immunity in } \\
\text { immunised populations }\end{array}$ \\
\hline & & $\begin{array}{c}\text { Ensure immunological studies, including neutralising antibody assays } \\
\text { for new SARS-CoV-2 variants of concern }\end{array}$ \\
\hline & Vaccine breakthrough infections & $\begin{array}{l}\text { Ensure routine monitoring of breakthrough infections through } \\
\text { notifiable systems and ensure timely reporting }\end{array}$ \\
\hline
\end{tabular}

COVID-19: coronavirus disease; EU/EEA: European Union/European Economic Area; RSV: respiratory syncytial virus; SARS-CoV-2: severe acute respiratory syndrome coronavirus 2 .

as early as the second quarter of 2021 for children aged 12-15 years. However-above all-community immunity through a combination of vaccine-induced immunity and natural immunity following infection will not provide full protection given the disparities in vaccine coverage from region to region and serious global vaccine shortages; it will take several years to reach a minimum of $70 \%$ coverage worldwide.

First laboratory studies and limited effectiveness studies suggest that the EU-authorised vaccines are protective against the B.1.1.7 variant first identified in Kent, UK, but are less protective against the B.1.351 and P.1. variants, first identified in the Cape region of South Africa and Manaus, Brazil, respectively [24,25]. There are no results available yet for the most recently identified new variants from India, B.1.617 and its subclades, which have more genetic changes compared with any other globally identified variant. The risk of breakthrough infection with the newly circulating SARS-CoV-2 VOCs in previously infected or vaccinated individuals is why all countries, including those with high vaccination coverage, may still maintain the non-pharmaceutical interventions used up to now, in order to offer individual- and population-level control against these variants. Guidance on how to safely ease 
control measures in exit strategies is already available, but when such measures can be safely lifted remains uncertain in the rapidly changing epidemiological landscape [26].

Within this context, one important population group to be monitored is immunocompromised people. They are expected to respond worse to vaccination, which may give rise to new SARS-CoV-2 variants if they are carrying virus for longer time periods. They may thus need effective treatments, e.g. in the form of antivirals, and effective antivirals will also be necessary to treat individuals hospitalised with severe COVID-19 disease.

As mentioned above, there are many remaining challenges in Europe and globally. Table 2 gives an overview of some important identified challenges and lists activities that are a shared responsibility between the national, regional and global levels using standardised methodology to allow for comparability of data collected.

While the world has been focused on COVID-19, the incidence of other respiratory pathogens such as seasonal influenza and respiratory syncytial virus (RSV) has diminished in many countries, most likely thanks to non-pharmaceutical control measures. Once life returns to normal-or closer to normal-these pathogens will return as well. While healthcare workers and public health efforts have been focused on COVID-19related activities, other sectors have suffered. Less attention to other vaccines in the national programmes and increased disparities as a result of the pandemic may lead to future outbreaks of other diseases. In this issue of Eurosurveillance, Rohleder et al. report that the risk of measles incidence in areas with the lowest deprivation quintile was 1.58 times higher (95\% credible interval (Crl):1.32-2.00) than in those with highest deprivation in Germany [27]. In the post-COVID-19 pandemic world, we need to be vigilant with these diseases. On the other hand, the pandemic has forced us to build and improve our adult vaccination infrastructure, as pointed out by Williams et al. in their global review, wherein they found that the Americas and Europe had the highest proportions of adult immunisation programmes, most commonly for hepatitis $B$ vaccine and influenza vaccines ( $>47 \%$ and $>91 \%$ of countries, respectively) [28]; however, now is the time to strengthen adult immunisation programmes and programmes targeted at healthcare workers, overall. Assessing protective immunity in healthcare workers for diseases with known correlates of protection is one possible strategy and opportunity, as shown in the article by von Linstow et al., also in this issue [29].

\section{Conclusions}

During the COVID-19 pandemic, important lessons for the future have been learnt on rapid vaccine development, authorisation, procurement, distribution and administration in large vaccination campaigns. Careful assessments of which technologies can provide safe and effective vaccines for all age and risk groups in the timeliest manner is now key moving forward.

Clinical trial networks conducting rapid trials taking into account the VOCs; genetic differences between global populations; and different age and risk groups, including underlying conditions such as obesity, being immunocompromised and other factors potentially influencing vaccine response, will likely also play an important role in future.

The possibility to administer COVID-19 vaccines to children and adolescents, who constitute a large part of the population worldwide, in some countries almost half of the population, should allow for a notable reduction in global transmission. Only after children and adolescents, as well as pregnant and lactating women, can safely be offered COVID-19 vaccines will it be likely that indirect protection is provided to groups that are unable to receive the vaccines themselves, such as those who are immunocompromised [30].

It should be noted that long-term safety and effectiveness are still unknown for the current and soon-to-be authorised vaccines in the EU and will guide the choice of vaccines to be recommended long-term.

The lessons from COVID-19 vaccination should help us to further expand adult immunisation programmes in general-and, in particular, for healthcare workers-beyond hepatitis B and influenza to pneumococcal, pertussis, herpes zoster and other future vaccines already under development, such as those against RSV. Exploring further how vaccines can be produced and distributed in an equitable manner is also necessary, since it is clear that no country or continent is on its own in ending the COVID-19 pandemic; international collaboration and global capacity building will be necessary to achieve this. Producing enough COVID-19 vaccines to equally serve every country in the world is an enormous challenge. Collaboration between vaccine developers, manufacturers, regulators, public health experts, governments and donors around the world will be key for continued vaccine development and global capacity building for vaccine production and deployment in all continents.

Finally, all of the decisions necessary for society to open up again should be evidence based at every step. To allow for such decision-making, well-designed surveillance systems and properly funded studies are necessary to critically appraise all implemented public health measures in the years to come. The tools to curb the COVID-19 pandemic are available to us, but we need to regularly assess them and use them in a scientifically sound manner. 


\section{Conflict of interest}

Kari Johansen: none declared.

Hanna Nohynek: Secretary of the THL NITAG, and chairman of the WHO SAGE covid-19 vaccines working group.

\section{References}

1. Cohen J. Chinese researchers reveal draft genome of virus implicated in Wuhan pneumonia outbreak. AAAS; 2020. Available from: https://www.sciencemag.org/news/2020/01/ chinese-researchers-reveal-draft-genome-virus-implicatedwuhan-pneumonia-outbreak

2. World Health Organization (WHO). WHO candidate tracker COVID-19 - Landscape of novel coronavirus candidate vaccine development worldwide. Geneva: WHO; 2021. Available from: https://www.who.int/publications/m/item/ draft-landscape-of-covid-19-candidate-vaccines

3. European Medicines Agency (EMA). EMA Guidance for medicine developers and other stakeholders on COVID-19. Amsterdam: EMA; 2020. Available from: https:// www.ema.europa.eu/en/human-regulatory/overview/ public-health-threats/coronavirus-disease-covid-19/ guidance-medicine-developers-other-stakeholders-covid-19

4. European Medicines Agency (EMA). EMA COVID-19: latest updates. Amsterdam: EMA; 2020. Available from: https:// www.ema.europa.eu/en/human-regulatory/overview/ public-health-threats/coronavirus-disease-covid-19/ covid-19-latest-updates

5. Vasileiou E, Simpson CR, Shi T, Kerr S, Agrawal U, Akbari $A$, et al. Interim findings from first-dose mass COVID-19 vaccination roll-out and COVID-19 hospital admissions in Scotland: a national prospective cohort study. Lancet. 2021;S0140-6736(21)00677-2. https://doi.org/10.1016/ S0140-6736(21)00677-2

6. Thompson MG, Burgess JL, Naleway AL, Tyner HL, Yoon SK, Meece J, et al. Interim estimates of vaccine effectiveness of BNT162 b2 and mRNA 1273 COVID-19 Vaccines in preventing SARS-CoV-2 infection among health care personnel, first responders, and other essential and frontline workers eight US locations, December 2020 - March 2021. MMWR Morb Mortal Wkly Rep. 2021;70(13):495-500. https://doi. org/10.15585/mmwr.mm7013e3 PMID: 33793460

7. Sadoff J, Gray G, Vandebosch A, Cárdenas V, Shukarev G, Grinsztejn B, et al. , ENSEMBLE Study Group. Safety and Efficacy of Single-Dose Ad26.COV2.S Vaccine against Covid-19. N Engl J Med. 2021; https://doi.org/10.1056/NEJMoa2101544 PMID: 33882225

8. European Centre for Disease Prevention and Control (ECDC). ECDC COVID-19 Vaccine tracker. Stockholm: ECDC. [Accessed: 28 Apr 2021]. Available from: https://qap.ecdc.europa.eu/ public/extensions/COVID-19/vaccine-tracker.html\#uptake-tab

9. COVAX. A global risk-sharing mechanism from pooled procurement and equitable distribution of COVID-19 vaccines. Geneva: Gavi. [Accessed: 28 Apr 2021]. Available from: https:// www.gavi.org/covax-facility

10. World Health Organization (WHO). WHO SAGE values framework for the allocation and prioritization of COVID-19 vaccination. Geneva: WHO; 2020. Available from: https://www. who.int/publications/i/item/who-sage-values-framework-forthe-allocation-and-prioritization-of-covid-19-vaccination

11. World Health Organization (WHO). WHO SAGE Roadmap For Prioritizing Uses Of COVID-19 Vaccines In The Context Of Limited Supply. Geneva: WHO; 13 Nov 2020. Available from: https://www.who.int/publications/m/item/ who-sage-roadmap-for-prioritizing-uses-of-covid-19vaccines-in-the-context-of-limited-supply-

12. European Centre for Disease Prevention and Control (ECDC). EU/EEA NITAG Collaboration. Stockholm: ECDC. [Accessed: 28 Apr 2021]. Available from: https://www. ecdc.europa.eu/en/about-us/partnerships-and-networks/ national-immunisation-technical-advisory-groups-nitag

13. Schultz NH, Sørvoll IH, Michelsen AE, Munthe LA, Lund-Johansen F, Ahlen MT, et al. Thrombosis and Thrombocytopenia after ChAdOx1 nCoV-19 Vaccination. $\mathrm{N}$ Engl J Med. 2021;NEJMoa2104882. https://doi.org/10.1056/ NEJMoa2104882 PMID: 33835768

14. Greinacher A, Thiele T, Warkentin TE, Weisser K, Kyrle PA, Eichinger S. Thrombotic Thrombocytopenia after ChAdOx1 nCov-19 Vaccination. N Engl J Med. 2021; https://doi. org/10.1056/NEJMoa2104840 PMID: 33835769
15. Scully M, Singh D, Lown R, Poles A, Solomon T, Levi M, et al. Pathologic Antibodies to Platelet Factor 4 after ChAdOx1 nCoV19 Vaccination. N Engl J Med. 2021;NEJMoa2105385. https:// doi.org/10.1056/NEJMoa2105385 PMID: 33861525

16. European Medicines Agency (EMA). Vaxzevria. Summary of product characteristics. Amsterdam: EMA. [Accessed: 28 Apr 2021]. Available from: https://www.ema.europa.eu/en/ documents/product-information/vaxzevria-previously-covid19-vaccine-astrazeneca-epar-product-information_en.pdf

17. Our world in data. England: Global Change Data Lab. [Accessed: 28 Apr 2021]. Available from: https:// ourworldindata.org/

18. World Health Organization (WHO). WHO R\&D Blueprint COVID-19 new variants: Knowledge gaps and research. Geneva: WHO; 12 Jan 2021. Available from: https://cdn.who.int/ media/docs/default-source/blue-print/covid-19-new-variants meeting-report_20.03.2012.pdf?sfvrsn=5ac5785_3\&downloa d=true

19. World Health Organization (WHO). Statement on the seventh meeting of the International Health Regulations (2005) Emergency Committee regarding the coronavirus disease (COVID-19) pandemic. Geneva: WHO; 19 Apr 2021. Available from: https://www.who.int/news/item/19-04-2021-statementon-the-seventh-meeting-of-the-international-healthregulations-(2005)-emergency-committee-regarding-thecoronavirus-disease-(covid-19)-pandemic

20. World Health Organization (WHO). WHO Weekly Epi Update from 13 April. Geneva: WHO; 2021. Available from: https://www.who.int/publications/m/item/ weekly-epidemiological-update-on-covid-19---13-april-2021

21. United States Food and Drug Administration (FDA). Coronavirus (COVID-19) Update: FDA Issues Policies to Guide Medical Product Developers Addressing Virus Variants. Washington: 22 Feb 2021. Available from: https://www.fda.gov/news-events/ press-announcements/coronavirus-covid-19-update-fdaissues-policies-guide-medical-product-developers-addressingvirus

22. European Medicines Agency (EMA). Regulatory requirements for vaccines intended to provide protection against variant strain(s) of SARS-CoV-2. Amsterdam: EMA; 25 Feb 2021. Available from: https://www.ema.europa.eu/en/regulatoryrequirements-vaccines-intended-provide-protection-againstvariant-strains-sars-cov-2

23. European Medicines Agency (EMA). EMA and ECDC join forces for enhanced post-marketing monitoring of COVID-19 vaccines in Europe. Amsterdam: EMA; 26 Apr 2021. Available from: https://www.ema.europa.eu/en/news/ema-ecdc-join-forcesenhanced-post-marketing-monitoring-covid-19-vaccineseurope

24. Moyo-Gwete T, Madzivhandila M, Makhado Z. SARS-CoV-2 501Y.V2 (B.1.351) elicits cross-reactive neutralizing antibodies; bioRxiv; 2021. Available from: https://www.biorxiv.org/content /10.1101/2021.03.06.434193V1

25. Cele S, Gazy I, Jackson L, Hwa SH, Tegally H, Lustig G, et al.; Network for Genomic Surveillance in South Africa. COMMITKZN Team. Escape of SARS-CoV-2 501Y.V2 from neutralization by convalescent plasma. Nature. 2021. https://doi. org/10.1038/s41586-021-03471-w PMID: 33780970

26. European Centre for Disease Prevention and Control (ECDC). ECDC Interim guidance on the benefits of full vaccination against COVID-19 for transmission and implications for nonpharmaceutical interventions. Stockholm: ECDC; 21 Apr 2021. Available from: https://www.ecdc.europa.eu/sites/default/ files/documents/Interim-guidance-benefits-of-full-vaccinationagainst-COVID-19-for-transmission-and-implications-for-nonpharmaceutical-interventions.pdf

27. Rohleder S, Stock C, Bozorgmehr K. Socioeconomic deprivation is inversely associated with measles incidence: a longitudinal small-area analysis, Germany, 2001 to 2017. Euro Surveill. 2021;26(17):1900755. https://doi.org/10.2807/1560-7917. ES.2021.26.17.1900755

28. Williams SR, Driscoll AJ, LeBuhn HM, Chen WH, Neuzil KM Ortiz JR. National routine adult immunisation programmes among World Health Organization Member States: an assessment of health systems to deploy COVID-19 vaccines. Euro Surveill. 2021;26(17):2001195. https://doi. org/10.2807/1560-7917.ES.2021.26.17.2001195

29. von Linstow ML, Yde NA, Kirkby N, Eltvedt A, Nordmann WT, Bybeck NA, et al. Immunity to vaccine-preventable diseases among paediatric healthcare workers in Denmark, 2019. Euro Surveill. 2021;26(17):2001167. https://doi.org/10.2807/15607917.ES.2021.26.17.2001167

30. European Centre for Disease Prevention and Control (ECDC). Objectives of vaccination strategies against COVID-19. Stockholm: ECDC; 23 Apr 2021. Available from: https://www.ecdc.europa.eu/en/publications-data/ objectives-vaccination-strategies-against-covid-19 
31. Robert Koch Institut (RKI). Standard Operating Procedure of the German Standing Committee on Vaccinations (STIKO) for the systematic development of vaccination recommendations, Version 3.1. Berlin: RKI; 14 Nov 2018. Available from: https:// www.rki.de/EN/Content/infections/Vaccination/methodology/ SOP.pdf? blob=publicationFile

\section{License, supplementary material and copyright}

This is an open-access article distributed under the terms of the Creative Commons Attribution (CC BY 4.0) Licence. You may share and adapt the material, but must give appropriate credit to the source, provide a link to the licence and indicate if changes were made.

Any supplementary material referenced in the article can be found in the online version.

This article is copyright of the authors or their affiliated institutions, 2021. 